\title{
Open innovation factors for higher education institutions.
}

\author{
Jose Ignacio Palacios-Osma ${ }^{1}$, Alexandra Abuchar-Porras ${ }^{2}$ \\ ${ }^{1,2}$ Universidad Distrital Francisco Jose de Caldas, Bogota - Colombia \\ ORCID: ${ }^{10000-0003-4701-4373}, \underline{20000-0001-8869-7129}$
}

Recibido: 27 de julio de 2020.

Aprobado: 11 de noviembre de 2020.

\begin{abstract}
Open innovation is a fundamental strategy in all institutions of higher education which allows them to achieve the goals and mission objectives, having as one of its essential purposes the generation and transfer of knowledge which is sup-ported and achieved by research groups and seedbeds generating innovation and development products of great impact, however, are not always incorporated to meet any requirement or provide solutions in society or in the productive sector among others. The article presents factors of open innovation, which must be analyzed, developed or strengthened within the institutions, therefore, while innovation has an important role, the application and adaptation requires disci-pline and integration with the organizational culture. The article identifies and describes the various components needed to incorporate open innovation in higher education institutions.
\end{abstract}

Keywords: Open innovation, higher education, Communication, Organizational alliances. 


\section{INTRODUCTION}

The information society has fostered the creation of diverse sce-narios such as collaborative learning, diverse business models, technologysupported businesses, gig economy, collaborative econ-omy, among others, which have promoted the strengthening of a mentality of entrepreneurship and innovation and therefore the con-solidation of competitive, flexible and collaborative productive sec-tors.

As a result of this current trend in organizational economics, there is an openness to the exchange of processes and knowledge among companies and with other sectors of the economy, academy and society, creating what is known as open innovation (InnA), understood as the result of a process that involves the use and ap-propriation of information technologies and communications, to facilitate the processing, storage and exchange of information among those involved in the development of research and innovation, with a significant reduction in transaction costs.

This InnA paradigm enters into controversy with some organi-zational theories; which consider as an advantage the use of own resources and means of production indicating that, within the organ-ization this has everything necessary to create a differentiating and competitive value, however, it is currently understood that these assumptions are not fully applicable, since currently business mod-els are open and collaborative, with mutual support among various actors or partners, which generates competitive advantages and risk mitigation, without the organization losing identity, value and control over itself.

In this sense, open innovation is part of this dynamic and of all types of organizations and in particular the need to create networks for obtaining resources and knowledge and therefore is a mechanism of strategic differentiation, where information, technologies, human talent, resources and knowledge are interwoven with different actors of the so-called quadruple helix (Companies - Academy - State - Society).

However, the university of the 21st century in Colombia must promote that its social and corporate value has a greater impact on its environment and where today there is a great interest coming from organizations to establish alliances with the different sectors and the university cannot be unaware of such dynamics, therefore it must strengthen and tighten the links with society, the productive sector and the government, thus consolidating the fourfold helix.

Consequently, the Institutions of Higher Education (IES) must establish a model of open and collaborative education, as well as develop a model of open management with strategic alliances that invite participation and exchange of knowledge and technology; as well as creating and establishing centers of innovation and develop-ment that allows the creation of environments of co-creation with different sectors of society.

Therefore, different levels are identified that lead to the integra-tion between the university and the productive sector, which begins with the consolidation of research groups and publications, then the creation of a integration office or link responsible for the consulting and research process, immediately accompanies the process of tech-nology transfer that has the task of managing intellectual property, patents and licenses that are the means of transfer and culminating in marketing models or innovation incubators, understood as compa-nies created by teachers, students and graduates of the institution.

However, by itself, the InnA is not implemented, it requires a process of preparation and maturity that allows the gradual integra-tion of this paradigm in the management model of the IES. In this sense, this article is the result of the systematic review of literature on the elements that provide or identify the organizational factors necessary in higher education institutions that allow them to integrate and implement a model of open innovation. The article, is developed in the following parts, as a first topic is exposed the importance and definition of open innovation, as a second point on how it converges in higher education, and in a third part the identification and descrip-tion of necessary factors to implement the process of open innova-tion applicable to the educational field, closing with the conclusions reached in the research.

\section{THEORETICAL FRAMEWROK}

\section{a. Open Innovation}

The processes of innovation are present in all the development of society through time and this is aligned with the whole inherent context of human being, therefore, the one that has to do with educa-tion. This article focuses on Higher Education Institutions (HEI) and the importance of developing a proposal to manage and implement open innovation at the academic level; with new ways of relating to all those involved internally or externally, which generates new ways of adapting to organizational dynamics, which implies the establishment of new forms of relationship allowing collaboration between the university and the business and industrial sector $[1,2]$.

Open innovation consists of taking advantage of knowledge available internally and externally by all actors who require it, which generates a win-win relationship with those who establish the InnA. It is important to clarify that companies must allow the availability of the results reached on their researches or define which can be shared or which are not relevant to their own institution and can be exchanged, thus facilitating the exchange of knowledge and technol-ogies and decide if are available for third parties $[3,4]$.

In 2003 the term Open Innovation was introduced by the author Chesbrough with the book "Open Innovation: The New Imperative for Creating and Profiting from Technology" [5], where he estab-lishes the need to work collaboratively, according to the author "from the outside in", and "from the inside out", this leads to a reflection of the entire organization where the needs can be defined and the business model identified, how it is being done?, where we are?, and where we want to arrive, among other aspects to be dis-cussed.

Chesbrough [6] develops and proposes a whole new paradigm about innovation and expresses how it has evolved becoming per-meable and cooperative to respond to the demands of competition, technology, the multiplication of global interactions along with the challenges and possibilities that these imply for research and devel-opment in the service of institutions.

Likewise, in one of the later publications Chesbrough [7,8], presents the advances that have been achieved and the general vision of open innovation as a growing aspect in both research and publica-tions, the implementation of it, showing an exponential growth in publications 
related to the subject and that have also gone from being published in business journals to magazines in the field of social sciences, through medical and computer science journals [9] which shows the growth and importance of open innovation, a concept that is also linked to issues of knowledge and technology $[10,11]$.

Therefore, there is no general and specific model of open inno-vation, so the institution must develop and structure its own model according to the context [12], however, it may adapt methods, tech-niques, tools, standards, methodologies, frameworks, good practic-es, among other aspects, highlighting the importance of human talent as vital to the commitment to openness and facilitate the exchange of knowledge and technology $[13,14]$.

In this sense, according to Chesbrough [15], the InnA is related to the entire process of the value chain, including research, develop-ment, manufacturing and marketing of products and services, a process where there is access to different resources, both internal and external, which implies that the organization improves its dy-namic capabilities to integrate external and internal knowledge. Thus, the InnA, creates a dynamic ecosystem where knowledge, infor-mation, ideas, projects, and therefore innovation, feeds back into the organizations and therefore to the environment, with the recognition of multiple actors who can contribute to research, knowledge and innovation.

\section{b. Open Innovation and Hiegher Education Institutions}

Higher education institutions are one of the most significant sources in the generation of knowledge and innovation, through the development, creation, dissemination, and socialization of research processes, carried out by students who will be future professionals, technologists and technicians, creating connections between different environments and establishing relationships with different actors and stakeholders, which can be used to implement solutions and im-provements $[16,17]$.

However, this transfer of knowledge is often not achieved in terms of development or research within the institutions, since it has been framed within itself and only for academic purposes, which prevents the transfer of knowledge with the productive sector and the state. On many occasions, the results of research are disseminat-ed through participation in academic events of different kinds, with-out this having an impact on the social, cultural and economic envi-ronment, on few occasions this transfer of knowledge materialize in the form of patents, licenses or industrial designs, among others. Traditionally, the university has focused on academic and scientific research [18], and only in recent years it has opened its borders, with various strategies to increase its impact on the environment.

Gradually, the limits of higher education have become more flexible and it has been accepted that knowledge, research and de-velopment are also done in different areas and sectors of society, which implies integrating efforts among all participants and thus creating synergies that allow such exchanges, with the respective recognition and intellectual property rights, where different practices of open innovation can be incorporated, both input and output [19].

Likewise, some developments, methodologies or processes im-plemented within the universities for their operation, are not ceased to be for internal use, without being exchanged or socialized with other HEIs for example, information systems created for academic-administrative purposes; quality models or quality management system; institutional accreditation models among others, which could be shared and improved with the collaborative work of several institutions [9].

Therefore, the challenge of higher education among many is pre-cisely open innovation, which will facilitate the integration of knowledge and information, both internally (research-teaching) and externally (community, other universities, productive sector) [20], which in turn implies a change in the model of administration and management, and consequently a way to establish relationships with multiple sectors, where processes of collaboration [21], co-creation, cross-licensing, research grants, R\&D alliances, announcements or challenges of innovation and incubation of companies among many other strategies and/or links with other actors and sectors of society converge [22].

At the same time, the university is immersed in various scenari-os such as digital technology, the Internet, open and free content and resources, networks and learning communities, which have emerged from the own community and different sectors of society, an exam-ple of this is the development of free applications such as Linux, Learning Management Systems (LMS- Open Source), and diversity of applications created by interest groups around a need or require-ment, where university as an institution has had little or no partici-pation.

For example, the case of one of the first Learning Management Systems (LMS), MOODLE (Module Object-Oriented Dynamic Learning Environment), developed since 1999, by the Australian Martin Dougiamas and released in 2002, today has more than 79 million users. Both in the case of Linux and Moodle, are examples of open innovation, which each has today learning and collaboration communities around the world and in different languages.

A similar situation is evidenced by the development of MOOCS (Massive Open Online Source) which represents another case of open innovation in learning processes, its participants are linked to courses on a voluntarily and with the interest of sharing and creating collaborative networks, under the paradigm of learning by doing, in that sense learning focuses on the student and his or her learning process [23]

In this model of Moocs, a set of platforms designed mostly by higher education institutions and open source, and then placed at the service of the entire academic community the benefits of the plat-form, for other institutions to create and share courses of free access and some of this platform has the support or endorsement of strate-gic allies in the business sector. In this context, some IES have progressively developed their MOOC-type courses.

The previous examples show once again the importance of the incorporation of open and collaborative innovation within higher education institutions, to the extent that the university no longer has a monopoly of knowledge and research, but on the contrary, in the Internet networks there is a lot of information generated by special-ists that allows free access to it. In this sense, the university must, on the one hand, adjust its way of managing knowledge, and on the other hand, do it in a collaborative and open way (Fig. 1). 


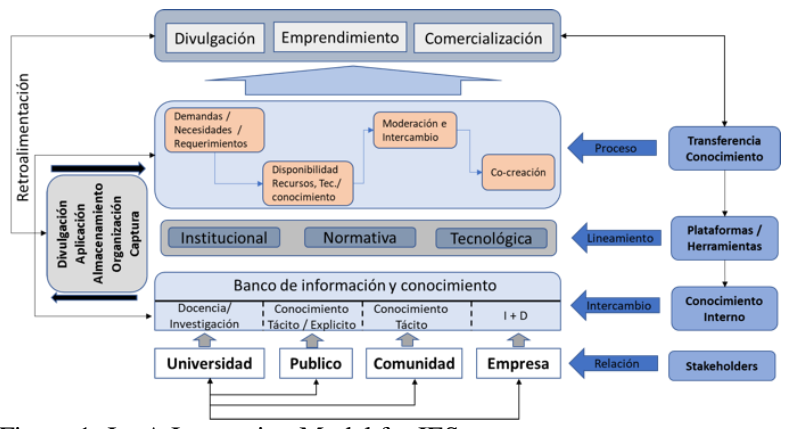

Figure 1: InnA Integration Model for IES.

Source: Own elaboration.

Therefore, higher education institutions and their research cen-ters as well as technology transfer offices, along with extension or social responsibility units, will increasingly need to participate in a collaborative and integrated manner with the different actors in society, businesses, industries, and with other research institutions, and to do so they must consolidate models and proposals for open innovation, as part of the institutional strategy and policies. This requires the implementation of plans, policies, projects and programs that facilitate its development, as well as initiating action with exter-nal agents, not only in the search for solutions, but also in obtaining resources that support and back up innovation.

\section{METHODOLOGY}

For the development and identification of InnA factors and to support research, a bibliographic review is carried out in the Web of Science (WoS), Science Direct and Scopus databases. This review is performed with the aim of obtaining the most relevant information in the field of study. The research followed the methodology of sys-tematic review of literature in order to classify, analyze and identify information on trends, and approaches of the InnA in the field of higher education.

As a first phase it established the objective of the research (InnA factors in the IES), and then the criteria for consultation in the data-bases were specified, the extraction of articles was carried out and finally they were studied. The search criteria used were:

(TITLE (open AND innovation) AND TITLE-ABS-KEY (higher AND education) OR TITLE-ABS-KEY (university)) AND DOCTYPE (ar OR re) AND ACCESSTYPE (OA)

It was studied a period comprehended between 2016 to 2020, taking into account those publications classified as article and ex-cluding those with no relation to university and any other sector in which this topics are being used.

A total of 67 documents were identified in Scopus, 42 docu-ments in Science Direct and in Web of Science 25. From this analy-sis, the following factors mentioned in several of the articles re-viewed are categorized and identified.

\section{OPEN INNOVATION FACTORS}

The factors associated with open innovation (InnA), which is proposed for the IES is the development of a common project with other entities, establishing conditions to define actions that allow the consolidation of open innovation in the institutions and thus innovate for responding to various kinds of needs, from different environments. According to the systematic review of literature carried out, the following factors have been identified that facilitate or promote the adequate incorporation of the InnA in higher education institutions: 1) Relational Capital: 2) Stakeholder Alliance; 3) Knowledge; 4) Communication; 5) New educational services and 6) Governance (Figure 2).

As shown in Figure 1, all these factors are related to each other, and are present in the development of projects in co-creation with the different sectors, such as sharing licenses or patents, generating new technologies, establishing spin-off models that allow the creation of communication channels with the productive sector and consequently facilitating the transfer of knowledge and open innovation.

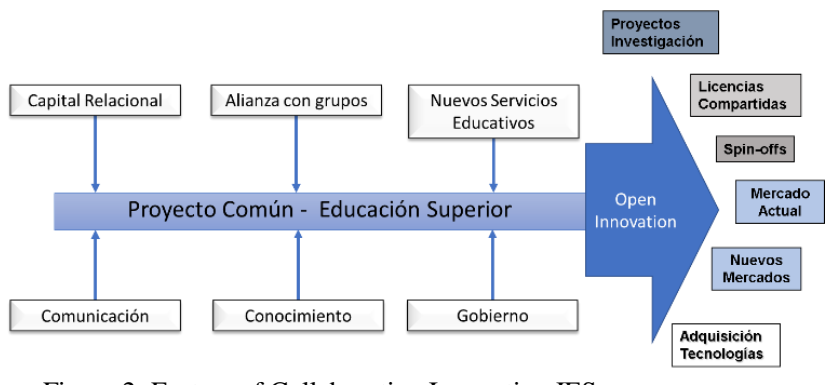

Figure 2: Factors of Collaborative Innovation IES. Source: Own elaboration. 


\section{a. Common Proyect}

Having a common project in the processes of open innovation is associated with the integration of resources, technologies and human talent in such a way that the university emphasizes research and preparation of human talent with knowledge, highlighting in students the skills and competencies needed to enable and enhance creativity and collaboration [24], as well as the use of different applications required in the process and the business sector supports what refers to possible resources; licensing, patents and designs; therefore education in this sense the transfer of knowledge must be executed according to a need that allows this form of innovation [25].

Likewise, the common project should be part of the consolidation of policies and strategies associated with the trust between the internal and external actors of the institution [26], since this implies openness and collaborative work, factors that should be promoted among the stakeholders for collaborative innovation at the level of the IES.

\section{b. Relational Capital}

Relational capital refers to the value that an institution has in the relations it maintains with the outside world, and the quality and sustainability with the users of the organization and its potential to generate new services and products are key factors for the success of the InnA, as is the knowledge that can be obtained from the relationship with other agents in the environment [27].

The latter takes on greater relevance in open innovation, as they are key elements for interdependent relations based on established cooperation [28], so it is clear that, by placing the university under the management of knowledge and information resources, it tends to be resized as a management center of information and producer of knowledge, which will make knowledge the heart and information in the research and development system of the institution [29].

Therefore, open innovation presents challenges related to the management of intellectual capital and in particular of relational capital in terms of the level of interaction necessary among participants [30]. On the other hand, Lenart-Gansiniec [31] mentions that relational capital has an important role in the organization and in particular in open innovation, to the extent that relationships are established with the environment that facilitates cooperation and exchange of resources among all parties. In the research carried out, the authors identify a relationship between open innovation and relational capital.

\section{c. Interest groups Alliances}

Organizations must have integration strategies, alliances between two or more organizations in order to join forces and enhance common objectives and thus have a mutual benefit. Therefore, it is important to identify who the interest groups or stakeholders are, meaning any individual or interest group explicitly or implicitly, voluntary or involuntary, that has to do with a process and can participate in the development of a particular service or product.

According to Freeman [32] the institution must be understood and conceptualized as a set of networked stakeholders who interact with one another in a constant and dynamic manner. These interactive relationships entail, among other things, the fact that there must necessarily be divergent and potentially conflicting interests; they also imply the possibility of establishing alliances between different agents or interest groups and overcoming the differences that may arise in co-creation.

\section{d. Knowledge}

Knowledge is a fundamental resource for the institution to be competitive; today it is the main intangible asset and/or human capital. Knowledge management should facilitate that knowledge is not lost and is preserved in the organization with the consequent benefit of its periodic consultation by the members of the organization. It must create a culture in the organization, in which knowledge is shared among its members. Staff who provide their knowledge should be rewarded and encouraged to use it by others [33].

It should encourage that tacit knowledge becomes explicit knowledge [34], in order to make innovation more competitive. Therefore, the information and knowledge must be identified and classified so that it can later be made available to those who participate in the collaborative development or with those involved in the development of innovation and research [35].

On the other hand, Guertler [36] shows that the implementation of a collaborative and open innovation model implies, among other factors, the following: a) staff / officials, b) governance, c) resources, d) process management, e) leadership and f) culture, which implies a process planning including partners (knowledge providers), collaboration models, establishing limitations and in general answering questions such as: how to do it?, when?, with whom?, for what purpose?, which implies a planning process of how to access knowledge and information.

Lazzorotti [37] considers that the implementation of open innovation processes, and because of its characteristics, requires the participation of all the actors of the institution insofar as it makes intensive use of the knowledge of individuals and of the organization.

\section{e. Communication}

Communication must be constant and continuous, decreasing the uncertainty that can be generated, making use of various interaction tools. The aim is for the response and communication to be timely and substantial, avoiding ambiguity, especially when individuals from different cultures and languages participate [38]. For González [39], communication is a success factor for open innovation, to the extent that the level of participation of each member and the understanding of the project are defined.

González [39] , considers that a success factor for innovation is communication, which he establishes in two dimensions: 1) Instrumental, referring to the process of transfer, assimilation and exploitation of knowledge, facilitating the agility of the learning process and 2) Behavioral, corresponding to the attitude and real use of ICT, with sincere and open exchange. 
Likewise, the Ministry of Information and Communication Technologies of Colombia also mentions that the success of collaborative innovation is linked to the following factors [40]: 1) Ensuring active participation: 2) Generating communication strategies that reach everyone: 3) Defining working groups that respect differences: 4) Creating a platform as a meeting point New educational services.

In this sense, higher education institutions should be considered for the economic development of a country. For Colombia, the analysis document "Visión Colombia II Centenario: 2019" of the Presidency of the Republic determines the impact of this innovation [41].

Educational services must be at the forefront of business requirements and technological developments, taking into account social and environmental responsibility and impact [42], without neglecting the development of human beings in all their dimensions, and the development of science and research. However, facing the processes of open innovation, the new educational services that are incorporated in a collaborative way, raises e-science model [43], open educational resources [44], licensing agreement [45], creation of university spin off [46, 47] and among other services.

\section{f. Government}

At the government level, open innovation must be established and strengthened as an organizational strategy, where the other administrative and management components of the HEI are integrated, in search of a strategic alignment, which supports the development of the substantive functions of the university, together with the incorporation of creativity as an essential component of research, innovation and the development of a model of Research, Development, innovation and creativity $(\mathrm{R}+\mathrm{D}+\mathrm{i}+\mathrm{c})$.

The incorporation of open innovation processes must firstly have a legal framework in terms of property rights of the developments and knowledge achieved, likewise the institution must facilitate the development of collaboration processes and exchange of information and knowledge, provided in its Corporate Governance, at the same time, and with regard to ICT, these will be strategically aligned with the policies and business model of the institution and therefore provide the technological platforms and means that allow the formation of innovation and participation networks, along with support for the operation of innovation communities that are formed [48].

As a complement to this alignment from the corporate government, technological management should be present and from the legal criteria of intellectual property and therefore from the innovation, institutions should consider this exchange of information and knowledge, and as a result of innovation, the impact that such services or products are achieved in the strategy of integration between the university community and the productive sector (Fig.3).

The open innovation model should promote the integration and flow of information and knowledge among the IES, the productive sector and the community, and each one of them with its different actors, stakeholders or sectors, with an organizational strategy that guarantees the exchange, property rights, developments, technological and social transfer of innovation, all supported by the use of information technologies as an environment of interaction and management, for which strategies should be defined to coordinate and integrate the implementation of open innovation [49] .

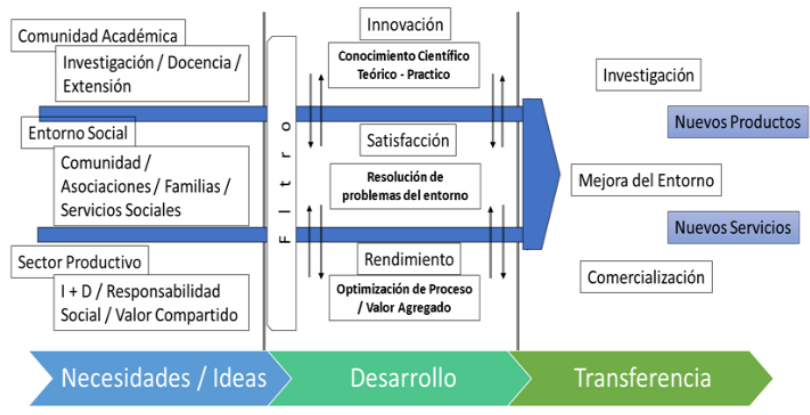

Figure 3: Open Innovation Processes IES.

Source: Own elaboration.

It is important that the leaders and/or directors of the institution show an interest, support and perspective in this innovation process, to the extent that open innovation processes must be institutionalized [50]. In this sense, the government of innovation will be associated with four factors identified by Giannopoulou [51] which are: 1) Open Business Model; 2) Value Co-creation; 3) Leadership for management; 4) Management of Intellectual Property.

\section{CONCLUSIONS}

With the above we can conclude that it is necessary to be at the forefront of new dynamics to be part of the changing process result-ing from the interrelationship with information and communication technologies which leads to establish new ways of connections and transfer of knowledge that are carried out within each organization and can project aspects of improvements and enhance new forms and ways of collaborative work. On the one hand, universities are able to concentrate the potential of human talent and establish differ-ent effective forms of cooperation, which requires consolidating a culture of open innovation. And, on the other hand, the productive and social sectors, have identified requirements and needs, which combined with the potential of the university manage to contribute synergistically to social and economic development.

It is determined that the process of open innovation is specific to each institution and should respond to a common project, therefore, it is concluded as one of the results of this project the importance of having the commitment and participation of corporate governance, as well as 
good management practices in the dissemination of infor-mation, to manage and share knowledge resulting from the various processes that take place in organizations.

The importance of the institution's commitment to human talent management was also determined since the open innovation model requires greater responsibility and participation in decision making. The need to develop for each university the general system of man-agement of interaction with companies or with the other actors of the quadruple helix was identified.

Open innovation has an important role in that it allows higher education to be aware of what is happening in the environment in which it is located, having greater and better contact with the com-munity; with society; with the business and productive sector, as well as being linked to state policies. In relation to the above, it is determined that it is necessary to have an organizational policy that provides the infrastructure and support necessary to generate an organizational culture of open innovation in the institutions.

Therefore, universities have become proactively involved in multiple areas, from technology transfer to the co-creation of knowledge. Societies and users have begun to form new concepts, R \& D \& I and marketing of the results, generating a dynamic of shared economy.

It can be noted from open innovation, that, as today, there is no organization that counts with all the necessary resources and knowledge to confront the society challenges and the productive sector and at the same time there is no study plans or curriculums that have the capacity to address all the knowledge and information that allow the complete development of a professional profile, which takes more relevance than the academic formation, aside from the conceptual basis that approach the problematics from the environ-ment and the search of inter and transdisciplinary solutions with the involved in the problematics.

In such way, it implies the integration of diverse activities, thus, from academy and investigation it is needed to explore and rethink the existing strategies of innovation and its relation with the knowledge networks and the creation of them, this are mentioned in literature but there are some few that are viable in the practice, this means that is needed to define the levels of collaboration, tools for open innovation management and specifically how to make effective this process of exchange and access to resources and technologies.

It must be highlighted that taking the open innovation as a stra-tegical component or a institutional key involves the creation of formation spaces and to give a innovation culture developing the teamwork, motivation, human resources skills, increase and stablish trust levels with thirds and give space to the commercialization of products of research in a direct ways or through others as part as the commercialization strategy.

The purpose of this work has been to identify which focus of the open innovation management, makes possible for institution of higher education improve the use and impact of research results in the groups of investigation and that their knowledge and expertise are available to different sectors of society and contribute to the development of region and nation.

With this preliminary study it is expected to encourage the de-velopment of new research, which will allow to guide the creation of models and strengthening of a culture of open innovation in higher education institutions and therefore this influences other society sectors.

\section{REFERENCES}

[1] S. Najafi-Tavani, Z. Najafi-Tavani, P. Naudé, P. Oghazi, and E. Zeynaloo, "How collaborative innovation networks affect new product performance: Product innovation capability, process innovation capability, and absorptive capacity," Industrial Marketing Management, vol. 73, pp. 193-205, 2018/08/01/ 2018, doi: https://doi.org/10.1016/j.indmarman.2018.02.009.

[2] S. Reichert, The Role of Universities in Regional Innovation Ecosystems, E. U. Association, ed., 2019. [Online]. Available: https://www.uw.edu.pl/wp-content/uploads/2019/03/eua-innovation-ecosystem-report-2019v1.1_final_digital.pdf. Accessed on: Junio 2020.

[3] H. Chesbrough, W. Vanhaverbeke, and J. West, New frontiers in open innovation: Oup Oxford, 2014.

[4] D. Li, A. Fast-Berglund, and D. Paulin, "Current and future Industry 4.0 capabilities for information and knowledge sharing," The International Journal of Advanced Manufacturing Technology, vol. 105, no. 9, pp. 3951-3963, 2019, doi: https://doi.org/10.1007/s00170019-03942-5.

[5] H. Chesbrough, Open innovation: The new imperative for creating and profiting from technology. Harvard Business Press, 2003.

[6] H. Chesbrough, C. Lettl, and T. Ritter, "Value creation and value capture in open innovation," Journal of Product Innovation Management, vol. 35, no. 6, pp. 930-938, 2018, doi: https://doi.org/10.1111/jpim.12471.

[7] T. Kohler and H. Chesbrough, "From collaborative community to competitive market: the quest to build a crowdsourcing platform for social innovation," R \& D Management, vol. 49, no. 3, pp. 356-368, Jun 2019, doi: https://doi.org/10.1111/radm.12372.

[8] H. Chesbrough and S. Brunswicker, "A fad or a phenomenon?: The adoption of open innovation practices in large firms," ResearchTechnology Management, vol. 57, no. 2, pp. 16-25, 2014, doi: https://doi.org/10.5437/08956308X5702196.

[9] B. Payán-Sánchez, L. J. Belmonte-Ureña, J. A. Plaza-Úbeda, D. Vazquez-Brust, N. Yakovleva, and M. Pérez-Valls, "Open Innovation for Sustainability or Not: Literature Reviews of Global Research Trends," Sustainability, vol. 13, no. 3, p. 1136, 2021, doi: $10.3390 /$ su13031136.

[10] J. J. Yun, E. Jeong, X. Zhao, S. D. Hahm, and K. Kim, "Collective Intelligence: An Emerging World in Open Innovation," Sustainability, vol. 11, no. 16, p. 4495, 2019, doi: https://doi.org/10.3390/su11164495.

[11] R. Vicente-Saez, R. Gustafsson, and L. Van den Brande, "The dawn of an open exploration era: Emergent principles and practices of open science and innovation of university research teams in a digital world," Technol. Forecast. Soc. Chang., vol. 156, p. 120037, 2020/07/01/ 2020, doi: https://doi.org/10.1016/j.techfore.2020.120037.

[12] C. H. Yuan, Y. Li, C. O. Vlas, and M. W. Peng, "Dynamic capabilities, subnational environment, and university technology transfer," Strategic Organization, vol. 16, no. 1, pp. 35-60, Feb 2018, doi: https://doi.org/10.1177/1476127016667969.

[13] Q. Liu, Q. Du, Y. Hong, W. Fan, and S. Wu, "User idea implementation in open innovation communities: Evidence from a new product development crowdsourcing community," Information Systems Journal, Article vol. 30, no. 5, pp. 899-927, 2020, doi: 10.1111/isj.12286. 
[14] C. Dell'Era, A. Di Minin, G. Ferrigno, F. Frattini, P. Landoni, and R. Verganti, "Value capture in open innovation processes with radical circles: A qualitative analysis of firms' collaborations with Slow Food, Memphis, and Free Software Foundation," Technol. Forecast. Soc. Chang., Article vol. 158, 2020, Art no. 120128, doi: 10.1016/j.techfore.2020.120128.

[15] M. Bogers, A. L. A. Burcharth, and H. Chesbrough, "Open Innovation in Brazil: Exploring Opportunities and Challenges," SSRN Electronic Journal, 2021, doi: 10.2139/ssrn.3778361.

[16] S. Leih and D. Teece, "Campus Leadership and the Entrepreneurial University: A Dynamic Capabilities Perspective," (in English), Acad. Manag. Perspect., Article vol. 30, no. 2, pp. 182-210, May 2016, doi: 10.5465/amp.2015.0022.

[17] E. C. Mayo, A. L. Gomez, and R. M. Fernandez, "Knowledge transfer from the innovative university. A model of information management in the digital context: the PIEDD case study," (in Spanish), Rev. Lat. Comun. Soc., Article vol. 74, no. 4, pp. 537-553, 2019, doi: https://doi.org/10.4185/rlcs-2019-1344-27.

[18] B. G. Salvat and P. L. Navarra, "Estrategias de innovación en la educación superior: el caso de la Universitat Oberta de Catalunya," Revista Iberoamericana de Educación, vol. 49, pp. 223-245. [Online]. Available: https://cutt.ly/AknhexX

[19] O. D. Ovuakporie, K. G. Pillai, C. Wang, and Y. Wei, "Differential moderating effects of strategic and operational reconfiguration on the relationship between open innovation practices and innovation performance," Research Policy, vol. 50, no. 1, p. 104146, 2021/01/01/ 2021, doi: https://doi.org/10.1016/j.respol.2020.104146.

[20] C. Tsinopoulos, C. M. P. Sousa, and J. Yan, "Process Innovation: Open Innovation and the Moderating Role of the Motivation to Achieve Legitimacy," (in English), Journal of Product Innovation Management, Article vol. 35, no. 1, pp. 27-48, Jan 2018, doi: https://doi.org/10.1111/jpim.12374.

[21] A. Mejía-Villa, M. Recalde, J. Alfaro, and E. Gutierrez, "Las asociaciones empresariales como comunidades de innovación colaborativa: desarrollo de un modelo teórico," pp. 1 - 29, 2017. [Online]. Available: https://cutt.ly/mkTy5E6.

[22] Wang T, Libaers, Dirk, and H. D. Park, "The Paradox of Openness: How Product and Patenting Experience Affect R\&D Sourcing in China?," Journal of Product Innovation Management, vol. 34, no. 3, pp. 250-268, 2017, doi: https://doi.org/10.1111/jpim.12359.

[23] D. Burgos and A. Tlili, "Openness as the key factor to support education in times of crisis," Eighth International Conference on Technological Ecosystems for Enhancing Multiculturality, pp. 1-4, 2020, doi: https://doi.org/10.1145/3434780.3436706.

[24] H. Kawai, "Open Innovation University-Industry Collaboration: Student Idea Contests and Exit Strategy in Japan," Japan Federation of Management Related Academies, vol. 1, no. 2, p. 31, 2017. [Online]. Available: http://www.jfmra.org/doc/jjm_vol01_no2.pdf\#page=37.

[25] K. Laine, M. Leino, and P. Pulkkinen, "Open Innovation Between Higher Education and Industry," Journal of the Knowledge Economy, vol. 6, no. 3, pp. 589-610, 2015, doi: https://doi.org/10.1007/s13132-015-0259-2.

[26] P. Maresova, I. Soukal, R. Stemberkova, and K. Kuca, "Innovation in the public sector in a small open economy-initial investigation of patent activity at the Czech universities," Journal of Innovation and Entrepreneurship, vol. 9, no. 1, 2020, doi: 10.1186/s13731-020-001175 .

[27] P. N. Zakharov, A. A. Posazhennikov, and Z. A. Zakharova, "Open Innovations as a Tool of Interaction Between Universities and Business Structures in the Digital Economy," Lecture Notes in Networks and Systems, Book Chapter vol. 87, pp. 301-306, 2020, doi: 10.1007/9783-030-29586-8_35.

[28] R. Lenart-Gansiniec, "Relational Capital and Open Innovation - in Search of Interdepencies," Acta Universitatis Agriculturae et Silviculturae Mendelianae Brunensis, vol. 64, no. 6, pp. 2007-2013, 2016, doi: 10.11118/actaun201664062007.

[29] X. Sun, H. Li, and V. Ghosal, "Firm-level human capital and innovation: Evidence from China," China Economic Review, vol. 59, p. 101388, 2020/02/01/ 2020, doi: https://doi.org/10.1016/j.chieco.2019.101388.

[30] L. Užienè, "Open Innovation, Knowledge Flows and Intellectual Capital," Procedia - Social and Behavioral Sciences, vol. 213, pp. 10571062, 2015, doi: 10.1016/j.sbspro.2015.11.525.

[31] R. Lenart-Gansiniec, "Relational Capital and Open Innovation - in Search of Interdependencies," Procedia - Social and Behavioral Sciences, vol. 220, pp. 236-242, 2016, doi: 10.1016/j.sbspro.2016.05.495.

[32] R. E. Freeman, A. C. Wicks, and B. Parmar, "Stakeholder Theory and "The Corporate Objective Revisited"," Organization Science, vol. 15, no. 3, pp. 364-369, 2004, doi: 10.1287/orsc.1040.0066.

[33] A. Bertello, A. Ferraris, P. De Bernardi, and B. Bertoldi, "Challenges to open innovation in traditional SMEs: an analysis of precompetitive projects in university-industry-government collaboration," Int. Entrep. Manag. J., 2021, doi: 10.1007/s11365-020-00727-1.

[34] L. Lam, P. Nguyen, N. Le, and K. Tran, "The Relation among Organizational Culture, Knowledge Management, and Innovation Capability: Its Implication for Open Innovation," Journal of Open Innovation: Technology, Market, and Complexity, vol. 7, no. 1, p. 66, 2021, doi: 10.3390/joitmc7010066.

[35] R. Huggins, D. Prokop, and P. Thompson, "Universities and open innovation: the determinants of network centrality," The Journal of Technology Transfer, pp. 1-40, 2019, doi: https://doi.org/10.1007/s10961-019-09720-5.

[36] M. R. Guertler, I. Michailidou, and U. Lindemann, "How to assess a company's open innovation situation?," Design Science, vol. 2, pp. 1 - 30, Feb 2016, doi: https://doi.org/10.1017/dsj.2016.4.

[37] V. Lazzarotti, R. Manzini, and L. Pellegrini, "Open innovation models adopted in practice: an extensive study in Italy," Measuring business excellence, 2010, doi: https://doi.org/10.1108/13683041011093721.

[38] H. H. Chang, C.-J. Hung, and H.-W. Hsieh, "Virtual teams: Cultural adaptation, communication quality, and interpersonal trust," Total Quality Management \& Business Excellence, vol. 25, no. 11-12, pp. 1318-1335, 2014, doi: https://doi.org/10.1080/14783363.2012.704274.

[39] R. González-Sánchez and F. E. García-Muiña, "Innovación abierta: Un modelo preliminar desde la gestión del conocimiento," Intangible capital, vol. 7, no. 1, 2011. [Online]. Available: http://hdl.handle.net/2099/10380.

[40] (2016). Plan Nacional de Ciencia, Tecnología e Innovación para el Sector TIC 2017-2022. [Online] Available: http://www.colciencias.gov.co/sites/default/files/plan-ctei-tic-2017-2022_0.pdf

[41] DNP, "2019 Visión Colombia II Centenario," Ministerio de Minas y Energía, Bogotá, vol. 2, 2006. [Online]. Available: https://archivo.cepal.org/pdfs/GuiaProspectiva/visionColombiaIIcentenario_2019comple.pdf.

[42] J. J. Martí-Noguera, I. C. Puerta-Lopera, and P. Rojas-Román, "A propósito de la Responsabilidad Social Universitaria," Revista Colombiana de Ciencias Sociales, vol. 8, no. 2, pp. 294-309, 2017.

[43] E. García Álvarez and J. López Sintas, "Ciencia abierta, e-ciencia y nuevas tecnologías: Desafíos y antiguos problemas en la investigación cualitativa en las ciencias sociales," Intangible capital, vol. 8, no. 3, 2012.

[44] A. S. Martín, J. L. C. Mendoza, and A. P. Martín, "Uso de Recursos educativos abiertos en Educación Superior," Universidad \& Ciencia, vol. 6, pp. 124-137, 2017. 
[45] (2005). Intercambiar valor - Negociación de acuerdos de licencia de tecnología. [Online] Available: http://www.wipo.int/edocs/pubdocs/es/licensing/906/wipo_pub_906.pdf

[46] H. Chesbrough and R. S. Rosenbloom, "The Role of the Business Model in Capturing Value from Innovation: Evidence from Xerox Corporation's Technology Spin-Off Companies," Industrial and Corporate Change, vol. 11, no. 3, pp. 529-555, 2002, doi: 10.1093/icc/11.3.529.

[47] M. T. Acytuno Pérez and M. A. Paz Báñez, "La creación de spin-off universitarias. El caso de la universidad de Huelva," Economía Industrial, no. 368, pp. 97-109, 2008. [Online]. Available: http://hdl.handle.net/10272/10810.

[48] A. Abbas, A. Avdic, P. Xiaobao, M. M. Hasan, and W. Ming, "University-government collaboration for the generation and commercialization of new knowledge for use in industry," Journal of Innovation \& Knowledge, vol. 4, no. 1, pp. 23-31, 2019, doi: https://doi.org/10.1016/j.jik.2018.03.002.

[49] K. Sudiana, E. T. Sule, I. Soemaryani, and Y. Yunizar, "The development and validation of the penta helix construct," Business: Theory and Practice, vol. 21, no. 1, pp. 136-145, 2020, doi: https://doi.org/10.3846/btp.2020.11231.

[50] S. Ollila et al., "An investigation into the roles of open innovation collaboration managers," R\&d Management, vol. 47, no. 2, pp. 236252, 2017, doi: 10.1111/radm.12197.

[51] E. Giannopoulou, A. Yström, and S. Ollila, "Turning open innovation into practice: Open innovation research through the lens of managers," International Journal of Innovation Management, vol. 15, no. 03, pp. 505-524, 2011. 